\title{
Diabetes Mellitus and Its Associated Risk Factors among adult Population in Bisha Province, Southwest of Saudi Arabia
}

\author{
Abdullah M. Al-Shahrani ${ }^{1}$, Mohammed A. Al-Saleem ${ }^{2}$, Mohamed O’haj ${ }^{3}$, Faleh Th. Mohammed ${ }^{4} \&$ Mutasim E. \\ Ibrahim $^{5}$ \\ ${ }^{1}$ Department of Family Medicine, College of Medicine, University of Bisha, Kingdom of Saudi Arabia \\ ${ }^{2}$ Department of Family Medicine, College of Medicine, King Khalid University, Kingdom of Saudi Arabia \\ ${ }^{3}$ Department of Biochemistry, College of Medicine, University of Bisha, Kingdom of Saudi Arabia \\ ${ }^{4}$ Diabetes Center, King Abdullah Hospital, Bisha, Kingdom of Saudi Arabia \\ ${ }^{5}$ Department of Medical Microbiology and Parasitology, College of Medicine, University of Bisha, Kingdom of \\ Saudi Arabia \\ Correspondence: Dr. Mutasim E. Ibrahim, College of Medicine, University of Bisha, P. O. Box 731 Bisha 63163, \\ Kingdom of Saudi Arabia. Tel: 96-650-265-6995. E-mail: mutasimhadi87@hotmail.com
}

Received: September 9, 2016 Accepted: October 8, 2016 Online Published: November 22, 2016

doi:10.5539/gjhs.v9n6p22 URL: http://dx.doi.org/10.5539/gjhs.v9n6p22

\begin{abstract}
Objectives: To determine the prevalence and associated risk factors of diabetes mellitus (DM) among the adult population in Bisha province, Saudi Arabia.

Methods: A cross sectional study was conducted during December, 2015 using the World Health Organization STEPS wise approach for data collection. Blood glucose level and anthropometric measurements of blood pressure, height, weight, and waist circumference were performed per standard methods. Logistic regression analysis was used to assess the prevalence and risk of diabetes.
\end{abstract}

Results: Of 542 adult individuals included in the study, 13.3\% (72) had diabetes, of which $8.1 \%$ were previously diagnosed and $5.2 \%$ represented new cases. The proportions of DM were $14.7 \%$ for men and $10.8 \%$ for women. Diabetes was significantly higher among married compared to unmarried individuals $(19.3 \%$ vs $5.5 \%$; $<<0.001)$ and among individuals aged $\geq 40$ years old compared to those $<40$ years $(31.3 \%$ vs $9.3 \% ; \mathrm{p}<0.001)$. The risk of diabetes was significantly increased with older age (Odds Ratio=4.470; 95\% CI 2.264-7.614), married individuals $(\mathrm{OR}=4.097 ; 95 \% \mathrm{CI} 2.188-7.672)$, weight/obesity $(\mathrm{OR}=2.827 ; 95 \%$ CI 1.567-5.072), hypertension $(\mathrm{OR}=4.383 ; 95 \%$ CI 2.085-9.214) and having a job (OR=2.327; $95 \%$ CI 1.347-4.02). The independent risk factors predicted diabetes were hypertension (Adjusted $\mathrm{OR}=2.897 ; 95 \%$ CI 1.269-66.13) and job patterns (Adjusted $\mathrm{OR}=2.793 ; 95 \% \mathrm{CI}$ 1.064-7.329).

Conclusion: Different risk factors alarming diabetes among adult population in Bisha province were detected. Strategies aimed to improving a healthy lifestyle are necessary to reduce the burden of the disease.

Keywords: diabetes, risk factors, adult population, Bisha province, Saudi Arabia

\section{Introduction}

Diabetes mellitus (DM) is a group of metabolic disorders characterized by chronic hyperglycemia condition due to defects in insulin secretion, insulin action, or both (American Diabetes Association [ADA], 2011). It has been associated with multiple medical complications that decrease the health-related quality of life and contribute to suboptimal physical and mental functioning and earlier mortality (Al Hayek et al., 2014). Individuals with DM have increased incidence of cardiovascular diseases, renal failure, hypertension and abnormalities of lipoprotein metabolism (ADA, 2011).

The global prevalence of DM is continuously increasing, representing a key public health issue (Abebe, Berhane, Worku \& Assefa, 2014; Sherif \& Sumpio, 2015). According to International Diabetes Federation (IDF, 2015), 415 million adults have diabetes in the world and this by 2040 will rise to 642 million. Saudi Arabia has been categorized as having the second highest rate of diabetes in the Middle East and the seventh highest prevalence of diabetes in the world (Robert et al., 2016). The IDF reported that there are 3.4 million cases of diabetes in Saudi 
Arabia in 2015, with a prevalence of $17.6 \%$ among adult aged between 20 to 79 years (IDF, 2015). Recently, there are huge an increasing rate of healthcare expense and treatment of diabetes, which costing the country around $14 \%$ of the total health expenses (Robert et al., 2016). However, a rapid socio-economic development has led to changes in major aspects of lifestyle patterns of the Saudi population towards urbanization and dietary habits as well (Al-Ghamdi, Al-Turki, Al-Baghli \& El-Zubaier, 2007; Ginter \& Simko, 2012). Moreover, a relationship between growing per capita income and economic development on the increase in diabetes prevalence have been well documented (Sherif \& Sumpio, 2015). The current published literatures shown that there are several risk factors related to the development of diabetes and its complications (Midhet, Al-Mohaimeed \& Sharaf, 2010; Zhao et al., 2012; Salam \& Siddiqui, 2013; Kyari et al., 2014). Hence, it is very important to determine associated risk factors to prevent or delay the onset of DM as well as to avoid the existence of life-threatening complications (Zhao et al., 2012). In Saudi Arabia, several studies have been conducted to determine the prevalence and associated risk factors of DM. For instance, a study conducted in the western region, mentioned that high risk groups should be identified and counseled early before the occurrence of diabetes (Murad, Abdulmageed, Iftikhar, \& Sagga, 2014). A case control study conducted in Al-Qassim, central region found that there are strong associations between diabetes and maternal history of diabetes, education, lack of exercise, and dietary habits (Midhet et al., 2010). Despite Saud Arabia is experiencing the highest relative increase in diabetes and its associated risk factors studied in many parts of the country(Al-Ghamdi et al., 2007; Salam \& Siddiqui, 2013; Al Hayek et al., 2014; Murad et al., 2014), but data are limited in Bisha regarding diabetes and its related risk factors (El-Hazmi et al., 1996) . Therefore, the present study aimed to assess the prevalence and associated risk factors of DM among adult population in Bisha province, southwest of Saudi Arabia.

\section{Materials and Methods}

\subsection{Study Design and Population}

This is a cross sectional study was conducted among the adult people of age ranged between 18 to 79 years old during December, 2015.

\subsection{Sample Size}

The sample size for the study was determined by assuming the prevalence of DM among adult people in Saudi Arabia to be $17.6 \%$ as recently described (IDF, 2015). A standard formula $(\mathrm{n}=\mathrm{z} 2 \times \mathrm{P}(100-\mathrm{P}) / \mathrm{d} 2)$ was used to calculate the sample size (Pourhoseingholi, Vahedi, \& Rahimzadeh, 2013), with the following parameters: $n=$ the number of samples; $Z=$ the level of statistical significant set up at the level of $95 \%$ confidence interval (1.96); $\mathrm{d}=$ the allowable error $(3.5 \%) ; \mathrm{P}=$ the anticipated prevalence $(17.6 \%)$. The minimum sample size obtained was 455 . Then $20 \%$ was considered to avoid non-response case, giving a total number of 546 .

\subsection{Study Area}

The study was conducted in Bisha province at southwest of Saudi Arabia. It is located in the northern part of the Aseer region, about 2,000 feet above sea level. Bisha has an estimated population of 205,346 according to the 2010 Census. Approximately 240 villages extent out on both sides of the Bisha valley, the longest valley in the country, and there are about 58 urban centers for gatherings (Bisha, World Public Library, 2016).

\subsection{Data Collection}

Data were collected by a trained team consisted of two physicians and three nurses. In addition to three faculty staff members and 12 medical students from the College of Medicine, University of Bisha. The World Health Organization (WHO) STEPS wise approach for collecting surveillance data for non-communicable diseases was used to collect prevalence data for diabetes their risk factors (WHO STEP wise approach, 2005). The participants were questioned about personal information and social-demographic characters, including, age, sex, nationality, marital status, occupation, income, education level, smoking, level of daily physical activity and family history of diabetes. Personal information that may break confidentiality of participants was not being included. The inclusion criteria were individuals those looking normal in physical apparent and willing to participate in the study. Whereas those were complaining from any disease or on fasting during the onset of the survey were excluded.

\subsection{Anthropometric Measurements}

After the interview of the participants, anthropometric measurements were performed, including height, weight, waist circumference (WC) using standardized methods and calibrated instruments. The (Body Mass Index) BMI was calculated as individual weight in kilograms divided by the height in meters squared as recommended by the WHO Expert Consultation, (2004). Physicians and nurses were carried blood pressure measurement from participants after several minutes in a seated position; using a blood pressure monitor. An average of twice 
readings of blood pressure taken one to two minutes apart was used for analysis. Then, peripheral blood sample by finger puncture was collected from each participant to estimate the blood glucose value using Accu-Check portable glucometer (Roche Diagnostics, GmbH, Mannheim, Germany) as previously described (Balaji, Madhuri, Paneerselvam, Arthi, \& Seshiah, 2012).

\subsection{Definition of Terms}

Increased BMI was defined as $\geq 25 \mathrm{~kg} / \mathrm{m}^{2}$. Abdominal obesity was defined as $\mathrm{WC}>102$ (men) and $>88 \mathrm{~cm}$ (women). WC was categorized as low risk if it was $93.9 \mathrm{~cm}$ or less for men, and $79.9 \mathrm{~cm}$ or less for women; high risk if it was $94 \mathrm{~cm}$ or more for men, and $80 \mathrm{~cm}$ or more for women (WHO Expert Consultation, 2004). Diabetes was defined as a self-reported positive history of diabetes or the reporting of random blood glucose level $\geq$ of 200 $\mathrm{mg} / \mathrm{dl}(11.1 \mathrm{mmol} / \mathrm{l})$ were established the diagnosis of DM (ADA, 2011). Hypertension was confirmed in regards to blood pressure of equal or greater than 140 (systolic)/90 (diastolic) $\mathrm{mm} / \mathrm{Hg}$ (Khatib \& El-Guindy, 2005).

\subsection{Statistical Analysis}

Statistical analysis was performed by the Statistical Package for Social Sciences, version 16.0 for Windows (SPSS Inc., Chicago, IL). Frequencies of demographic and clinical variables were entered and analysed. Chi square test was used to determine statistical significance between each two variables with all $p$ values of $<0.05$ were considered statistically significant. The risk of diabetes was assessed in relation to socio-demographic and biophysical factors using univariate logistic regression analysis. Then, variables with $p$-value of $<0.1$ were further analyzed in the multivariate logistic regression model.

\subsection{Ethical Consideration}

Ethical approval was obtained from the research committee, College of Medicine, University of Bisha. Participants were recruited voluntarily after informing them about the purpose of the study and confidentiality of the data and anonymity. A written consent was taken from those were agreed.

\section{Results}

A total of 546 adult population were targeted for the study, however, 542 (99.2\%) individuals were participated and contributed full information. Of the 542 participants included, $348(64.2 \%)$ were men and $194(35.8 \%)$ women. The majority of the participants $(81.7 \%)$ were in age below 40 years old. Of the total number of participants, 306 $(56.5 \%)$ were married, $300(55.4 \%)$ having jobs and $252(46.5 \%)$ were within or having university or post-graduation level. Individuals being overweight or obese were recorded at $58.3 \%$. There was a family history of diabetes in $47.8 \%$ of participants. Distribution of sociodemographic and clinical characteristics of the study participants presented in Table 1 .

Table 1. Sociodemographic and clinical characteristics of study participants $(\mathrm{n}=542)$

\begin{tabular}{lll}
\hline Characteristic & Number & Percentage \\
\hline Gender & 348 & 64.2 \\
Men & 194 & 35.8 \\
Women & & \\
Age & 99 & 18.3 \\
$\geq 40$ & 443 & 81.7 \\
$<40$ & & \\
Marital Status & 306 & 56.5 \\
Married & 236 & 43.5 \\
Non-Married & & \\
Education & 290 & 53.5 \\
High school or below & 252 & 46.5 \\
University or higher & & \\
Obesity & 316 & 58.3 \\
Obesity/overweight & & \\
\hline
\end{tabular}


Normal weight

Diabetes

Yes

No

Hypertension*

Yes

No

Job

Yes

No

Smoking

Currently/previously

87

455

Never

Exercise

No

Yes

Family history of Diabetes

Yes

No

Vegetable and fruit intake

Not-daily

Daily

226

$$
72
$$

470

41.7

86.7

*missing values excluded.

\subsection{Prevalence of Diabetes}

The prevalence of diabetes by several socio-demographic and biophysical variables are shown in Table 2 . Out of the total number of the study participants $(\mathrm{n}=542)$, the prevalence of DM found to be at $13.3 \%(72 / 542)$, of which $8.1 \%$ were previously diagnosed, whereas $5.2 \%$ were newly detected cases. The proportions of DM were $14.7 \%$ $(41 / 348)$ for men and $10.8 \%(31 / 194)$ for women. Diabetes was significantly higher among married in comparable to unmarried individuals $(19.3 \%$ vs $5.5 \% ; \mathrm{p}<0.001)$. The prevalence of diabetes was higher among aged individuals equal or more than 40 years old compared to those under 40 years $(31.3 \%$ vs $9.3 \%$; $<0.001)$. Individuals with DM were more likely to be hypertensive and to be overweight (Table 2). The proportions of DM were not statistically significant $(p>0.05)$ according to gender $(p=0.236)$, physical exercise $(p=0.301)$, smoking habits $(\mathrm{p}=0.607)$ and frequency of vegetable and fruit intakes $(\mathrm{p}=0.140)$.

Table 2. Prevalence of diabetes by socio-demographic and biophysical factors among adult population in Bisha province, southwest of Saudi Arabia

\begin{tabular}{llll}
\hline Characteristic & Total Number (\%) & No of diabetes (\%) & P value \\
\hline Gender & & & \\
Men & 348 & $51(14.7)$ & \\
Women & 194 & $21(10.8)$ & \\
\hline Age & & & $<0.001$ \\
$\geq 40$ & 99 & $31(31.3)$ & \\
\hline
\end{tabular}




\begin{tabular}{|c|c|c|c|}
\hline$<40$ & 443 & $41(9.3)$ & \\
\hline \multicolumn{4}{|l|}{ Marital Status } \\
\hline Married & 306 & $59(19.3)$ & $<0.001$ \\
\hline Non-Married & 236 & $13(5.5)$ & \\
\hline Education & & & 0.009 \\
\hline High school or below & 290 & $49(16.9)$ & \\
\hline University or higher & 252 & $23(9.1)$ & \\
\hline Obesity & & & $<0.001$ \\
\hline Obesity/overweight & 316 & $56(17.7)$ & \\
\hline Normal weight & 226 & $16(7.1)$ & \\
\hline Hypertension $^{*}$ & & & $<0.001$ \\
\hline Yes & 38 & $14(36.8)$ & \\
\hline No & 315 & $37(11.7)$ & \\
\hline \multicolumn{4}{|l|}{ Job } \\
\hline Yes & 300 & $52(17.3)$ & 0.002 \\
\hline No & 242 & $20(8.3)$ & \\
\hline Smoking & & & 0.619 \\
\hline Currently/previously & 87 & $13(14.9)$ & \\
\hline Never & 455 & $59(13.0)$ & \\
\hline \multicolumn{4}{|l|}{ Exercise } \\
\hline No & 328 & $48(14.6)$ & 0.253 \\
\hline Yes & 214 & $24(11.2)$ & \\
\hline \multicolumn{4}{|c|}{ Family history of Diabetes } \\
\hline Yes & 259 & $43(16.7)$ & 0.028 \\
\hline No & 283 & $29(10.2)$ & \\
\hline \multicolumn{4}{|c|}{ Vegetable and fruit intake } \\
\hline Not Daily & 363 & $43(11.8)$ & 0.140 \\
\hline Daily & 179 & $29(16.4)$ & \\
\hline
\end{tabular}

*missing values excluded.

\subsection{Multivariate Analysis of Risk Factors of Diabetes}

Results of univariate and multivariate analysis on the risk factors associated with diabetes is shown in Table 3. In univariate analysis, the risk of diabetes was found to be significantly increased with the presence of the following factors: being age above 40 years (Odds Ratio $(\mathrm{OR})=4.470 ; 95 \%$ CI 2.264-7.614), being married (OR=4.097; $95 \%$ CI 2.188-7.672), having low educational degree ( $\mathrm{OR}=2.024 ; 95 \% \mathrm{CI} 1.195-3.430)$, increasing weight/obesity $(\mathrm{OR}=2.827 ; 95 \%$ CI $1.567-5.072)$, being hypertensive $(\mathrm{OR}=4.383 ; 95 \%$ CI $2.085-9.214)$, having a job $(\mathrm{OR}=2.327 ; 95 \% \mathrm{CI} 1.347-4.02)$ and with the family history of diabetes $(\mathrm{OR}=1.759 ; 95 \% \mathrm{CI} 1.062-2.913)$. Based on the results of multivariate logistic regression analysis, the independent risk factors that predicted the prevalence of diabetes were hypertension (Adjusted $\mathrm{OR}=2.897 ; 95 \%$ CI 1.269-66.13) and job patterns (Adjusted OR=2.793; 95\% CI 1.064-7.329) (Table 3). 
Table 3. Univariate and multivariate analysis of risk factors associated with diabetes

\begin{tabular}{|c|c|c|c|c|c|}
\hline Variable & $\begin{array}{l}\text { With Diabetes } \\
\text { N (\%) }\end{array}$ & OR $(95 \% \mathrm{CI})$ & Pvalue & AOR $(95 \% \mathrm{Cl})$ & P value \\
\hline Gender & & & 0.209 & - & \\
\hline Men & $51(14.7)$ & $1.415(0.823-2.432)$ & & & \\
\hline Women & $21(10.8)$ & reference & & & \\
\hline Age & & & $<0.001$ & & 0.053 \\
\hline$\geq 40$ year & $31(31.3)$ & $4.470(2.264-7.614)$ & & $2.008(0.992-4.067)$ & \\
\hline$<40$ & $41(9.3)$ & reference & & reference & \\
\hline Marital Status & & & $<0.001$ & & 0.086 \\
\hline Married & $59(19.3)$ & $4.097(2.188-7.672)$ & & $2.333(0.888-6.127)$ & \\
\hline Unmarried Married & $13(5.5)$ & reference & & reference & \\
\hline Education & & & 0.009 & & 0.070 \\
\hline Higher school or below & 49 (16.9) & $2.024(1.195-3.430)$ & & $1.916(0.948-3.873)$ & \\
\hline University or higher & $23(9.1)$ & reference & & reference & \\
\hline Obesity & & & $<0.001$ & & 0.384 \\
\hline Obesity/overweight & $56(17.7)$ & $2.827(1.567-5.072)$ & & $1.398(0.658-2.968)$ & \\
\hline Normal weight & $16(7.1)$ & reference & & reference & \\
\hline Hypertension & & & $<0.001$ & & 0.012 \\
\hline Yes & $14(36.8)$ & $4.383(2.085-9.214)$ & & $2.897(1.269-66.13)$ & \\
\hline No & $37(11.7)$ & reference & & reference & \\
\hline Job & & & 0.002 & & 0.037 \\
\hline Yes & $52(17.3)$ & $2.327(1.347-4.02)$ & & $2.793(1.064-7.329)$ & \\
\hline No & $20(8.3)$ & reference & & reference & \\
\hline Smoking & & & 0.619 & & \\
\hline Currently/previously & $13(14.9)$ & $1.179(0.616-2.258)$ & & - & \\
\hline Never & $59(13.0)$ & reference & & & \\
\hline Exercise & & & 0.253 & & \\
\hline No & $48(14.6)$ & $1.357(0.804-2.291)$ & & - & \\
\hline Yes & $24(11.2)$ & reference & & & \\
\hline Family History of Diabetes & & & 0.028 & & 0.113 \\
\hline Yes & $43(16.7)$ & $1.759(1.062-2.913)$ & & $1.706(882-3.300)$ & \\
\hline No & $29(10.2)$ & reference & & reference & \\
\hline Vegetable and Fruit Intake & & & 0.140 & & 0.338 \\
\hline Not- Daily & $43(11.8)$ & $0.682(0.409-1.134)$ & & $0.733(0.378-1.423)$ & \\
\hline Daily & $29(16.4)$ & reference & & reference & \\
\hline
\end{tabular}

Note. $\mathrm{OR}=$ Odd Ratio; $\mathrm{CI}=$ Confidence Interval; $\mathrm{AOR}=$ Adjusted Odd Ratio.

\section{Discussion}

Diabetes is one of the common emerging public health problems known in Saudi Arabia (Al Hayek et al., 2014; Robert et al., 2016). To the best of our knowledge, this is the first study, estimate the prevalence of diabetes and its associated risk factors among adult population in Bisha province in the southwest region. In this study, the prevalence of DM among adult people in Bisha was $13.3 \%$. This proportion is higher than $5.2 \%$ and $6 \%$ reported 
earlier between 1991 to 1995 among the adult population in Bisha (El-Hazmi et al., 1996). Moreover, our result was greater than $4.1 \%$ reported in Riyadh region in 2000 (Karim, Ogbeide, Siddiqui, \& Al-Khalifa, 2000). Nevertheless, our finding was lower compared to $22.4 \%$ reported in Jazan district (Hajar, Hazmi, Wasli, Mousa, \& Rabiu, 2015) and $17.2 \%$ in the eastern province of Saudi Arabia (Al-Baghli et al., 2010). Obviously, our current results are in consistent with different reports from the country, indicating that the rates of diabetes are continuously increasing and representing potential health burdens. The high prevalence of DM in many parts of Saudi Arabia could be due to many causes ranging from socio-demographic to biophysical factors (Murad et al., 2014). In the present study, we identified a combination of risk factors that associated with diabetes. Interestingly, the strong association of DM with several risk factors was observed in our study, which is in agreement with other studies in many parts of the world [10,12,24,25] (Valdez, Yoon, Liu, \& Khoury, 2007; Zhao et al., 2012; Connor et al., 2013; Kyari et al., 2014). In the present study, the frequency of DM was slightly higher among men (14.7\%) compared to women (10.8\%). Likewise, Al-Nozha et al. (2004) found that males were overall having higher prevalence of DM than females in Riyadh capital, Saudi Arabia. Similar findings have been reported in the neighboring countries, such as in Sultanate Oman (El-Shafie \& Rizvi, 2010) and in Kuwait (Ahmed, Waslien, Al-Sumaie, Prakash \& Allafi, 2013). In addition, the association between diabetes and gender has been the focus of several studies with varying reports. For instance, slightly higher prevalence of diabetes among men than women was recorded in Indonesia (Soegondo, Widyahening, Istantho, \& Yunir, 2011) and Spain (Soriguer et al., 2012). Furthermore, no significant difference was observed in the total prevalence of diabetes among men and women in China (Xia et al., 2013) and South Asian countries (Akter, Rahman, \& Abe, 2014; Zaman \& Borang, 2014; Amarasinghe, Balakumar \& Arasaratnam, 2015). We found that married individuals have at a greater risk of diabetes when compared to unmarried people. This in compatible with other findings of studies conducted in the central region (Al-Aboudi, Hassali, Shafie, Hassan, \& Alrasheedy, 2015) and the eastern province of Saudi Arabia (Al-Baghli et al., 2010). Our finding could be explained by the fact that unmarried individual has a free of social commitment, thus might have more time for doing exercise and has ability to control his diet in a proper way (Salam \& Siddiqui, 2013). In this study, we have found contrary associations between diabetes and educational level, where an increasing degree of education related to reduction of diabetes ratio. A similar observation was recorded in another study in Saudi Arabia (Al-Baghli et al., 2010). It has been observed that individuals with low educational level at higher risk of having DM, after adjustment for other risk factors that related with diabetes (Soriguer et al. 2012). This might attributed to better-education leads people to improve healthier lifestyles (Xia et al., 2013).

According to our findings, increasing age was an important risk factor associated with DM in Bisha province, which is in agreement with other reports from other parts of Saudi Arabia (Al Hayek et al., 2014; Amin et al., 2014; Murad et al., 2014) and neighboring countries (Ahmed et al., 2013; Ali, Mehrass, Al-Adhroey, Al-Shammakh \& Amran, 2016). Ammarasinghe et al. (2015) proposed that geriatric changes in the body systems might invariably contribute to this association. In addition, hada et al. (2014) suggested that aging causes a progressive decline in the strength and endurance of musculature, which causes muscle atrophy, the risk of developing Type 2 DM increases. On the other hand, perhaps could be due to decreasing of physical activity explains the excess prevalence of such age group. Moreover, with increasing age, adipose deposition could be increased which might lead to insulin resistance and increasing rates of blood glucose and blood pressure (Amarasinghe et al., 2015). In consistent with other studies in Saudi Arabia (Al-Nozha et al., 2004; Al Hayek et al., 2014; Amin et al., 2014) and in many parts of the world (Soegondo et al., 2011; Soriguer, et al., 2012; Xia et al., 2013; Akter et al., 2014; Amarasinghe et al., 2015), our report revealed that individuals with high body weight were more likely to develop diabetes. Excess body fat well documented as being a risk factor for various chronic conditions such as diabetes, hypertension, hyperlipidemia and cardiovascular diseases (Kamadjeu et al., 2006). The stability of economic and technological progress in oil producing countries such as Saudi Arabia has been reported as promoting factor for obesity (Ginter \& Simko, 2012; Amin et al., 2014). A study in Saudi Arabia has shown that changes in food consumption towards a high-energy-density with fattiest food with a decline in the intake of fruit, vegetables also have a significant role of overweight and diabetes (Midhet et al., 2010). In addition, environmental factors, the lack of physical activity and sedentary lifestyle are being important factors that contribute to the increased prevalence of obesity in the gulf countries (Al-Nohair, 2014; Al-Shehri et al., 2016). Therefore, reducing modifiable dietary and lifestyle change could decrease the incidence of diabetes (Adede et al., 2014; Akter et al., 2014; Al-Shehri et al., 2016).

The prevalence of hypertension, a major risk factor for diabetic is also in high rates recorded in previous studies in Saudi Arabia (Al-Ghamdi et al., 2007; Amin et al., 2014). In the present study, our result revealed that hypertension is the strongest risk factor associated with DM (OR 4.383; 95\% CI 2.085-9.214). A study conducted 
in Spain showed that the presence of diabetes was significantly associated with high blood pressure (OR 2.26 [1.77, 2.87]) (Soriguer et al., 2012). Another a study from Sultanate Oman found that $70 \%$ of the diabetic patients were found to have high blood pressure (El-Shafie \& Rizvi, 2010). Likewise, elsewhere studies have been reported that the risk of diabetes was greater in individuals with hypertension than in those without (Xia et al., 2013; Akter et al., 2014; Zaman \& Borang, 2014). Since hypertension is well known to contribute to diabetic vascular complications. Thus, prevention strategies should be adopted to control the blood pressure in diabetic's patients (El-Shafie \& Rizvi, 2010). In this study, family history of diabetes is a common risk factor of the disease. Similar results have been reported in Arab countries (Sherif \& Sumpio, 2015; Ali et al., 2016) and Europe (Soriguer et al., 2012; Connor et al., 2013). Previous studies in the United States, have reported that family history of diabetes has a significant, independent, and graded association with the prevalence of diabetes in US population (Hariri et al., 2006; Valdez et al., 2007). Numerous genetic variants, lifestyles and living environments within the families might play an important role in the development of diabetes in the family members (Al-Baghli et al., 2010; Adede et al., 2014). Moreover, having a family history of diabetes is not only a risk factor for the disease but is also completely associated with risk awareness and risk-reducing behaviors. It may provide a useful screening tool for detection and prevention of diabetes (Hariri et al., 2006).

In the present study, $55.4 \%$ of the participants were reported to have a job. In addition, we found that job to be a strong predictor risk factor for development of diabetes (AOR 2.793; 95 CI 1.064-7.329). A previous study, reported that job strain was associated with a twofold higher risk of type 2 diabetes (Hazard Ratio 1.94 [95\% CI 1.17-3.21]) (Heraclides, Chandola, Witte, \& Brunner, 2009). In addition, sedentary lifestyle and the long period of sitting in the workplace for hours have been observed as major risk of DM (Amarasinghe et al., 2015). Different studies show that breaking up prolonged sitting has beneficial associations in reduction of WC, BMI, glucose and insulin levels in overweight/obese adults (Dunstan et al., 2012; Larsen et al., 2014; Thorp et al., 2014). Therefore, further study on job patterns is important to clearly understand the link between specific types of the job and progression of diabetes in our setting. Chronic smoking is known to induce insulin resistance, inadequate compensatory insulin secretion responses and develop type 2 diabetes (Zhao et al., 2012). In the present study, there was no significant difference observed in the proportion of diabetes among the smokers compared to non-smokers $(\mathrm{OR}=1.179 ; 95 \% \mathrm{CI} 0.616-2.258 ; \mathrm{p}=0.607)$. In contrary, Ammarasinghe et al. (2015) reported that the odds ratio for development of DM among the smokers was significantly higher when compared with non-smokers $(\mathrm{p}=0.032)$. Similarly, various studies have also investigated the association between diabetes and smoking habits (Soriguer et al., 2012; Amin et al., 2014).

The study has several limitations. Firstly, diagnosis of DM in the present study depends on the estimation of RBS sample with cutoff value $200 \mathrm{mg} / \mathrm{dl}$, which might miss many cases with altered glucose intolerance and diabetes. Secondly, diabetes was not classified as type 1 or type 2, and information on the duration of diabetes was not mentioned. Thirdly, the positive samples with diabetes obtained in this study were not sufficient to carry out detailed analyses of the various risk factors such as age group classifications and types of occupation. Fourthly, the conservative nature of the Saudi society may hinder some details on exposures such as smoking habits, which is not a suitable question for women. In addition, some of the information was based on self -reporting data, which is subject to recall bias. Finally, although, Bisha city surrounded by many villages and rural areas, the study did not categorize the population according to the rural and urban living.

In conclusions, the present study showed that the prevalence of diabetes among adult population in Bisha province is increasing in consistent with many studies in Saudi Arabia. The study identified that hypertension and job patterns were independent risk factors that predicted the prevalence of diabetes. Family history of diabetes, obesity/overweight, age, marital status and educational degree were important factors found to increase the risk of diabetes. A healthy lifestyle should also be developed through primary prevention strategies and promote awareness over behavior change programs. The current data will be significant for the development of health systems and services to respond to the growing burden of diabetes and its associated risk factors in our study area.

\section{Competing of Interest}

The authors declare no competing interests.

\section{Acknowledgements}

The authors would like to express their grateful to all study participants. We would like to thank to Dr. Ahmed Shawki and Mr Fahad Mosfir Alharthy for conducting the study measurements. Our grateful goes to Mr. Fawaz Higla for his excellent coordination. Special thanks to our medical students at the College of Medicine, University of Bisha for their help and assistance. 


\section{Competing Interests Statement}

The authors declare that there is no conflict of interests regarding the publication of this paper.

\section{References}

Abebe, S. M., Berhane, Y., Worku, A. \& Assefa, A. (2014). Diabetes mellitus in North West Ethiopia: a community based study. BMC Public Health, 14, 97. http://dx.doi.org/10.1186/1471-2458-14-97

Ahmed, F., Waslien, C., Al-Sumaie, M. A., Prakash, P., \& Allafi, A. (2013). Trends and risk factors of hyperglycemia and diabetes among Kuwaiti adults: National Nutrition Surveillance Data from 2002 to 2009. BMC Public Health, 5(13), 103. http://dx.doi.org/10.1186/1471-2458-13-103

Akter, S., Rahman, M. M., Abe, S. K., \& Sultana, P. (2014). Prevalence of diabetes and prediabetes and their risk factors among Bangladeshi adults: a nationwide survey. Bulletin of the World Health Organization, 92(3), 204-213A. http://dx.doi.org/10.2471/BLT.13.128371

Al Hayek, A. A., Robert, A. A. , Al Saeed, A., Alzaid, A. A., \& Al Sabaan, F. S. (2014). Factors Associated with Health-Related Quality of Life among Saudi Patients with Type 2 Diabetes Mellitus: A Cross-Sectional Survey. Diabetes and Metabolic Journal, 38(3), 220-229. http://dx.doi.org/10.4093/dmj.2014.38.3.220

Al-Aboudi, I. S., Hassali, M. A., Shafie, A. A., Hassan, A., \& Alrasheedy, A. A. (2015). A cross-sectional assessment of health-related quality of life among type 2 diabetes patients in Riyadh, Saudi Arabia. SAGE Open Medicine, 3, 2050312115610129. http://dx.doi.org/10.1177/2050312115610129

Al-Baghli, N. A., Al-Ghamdi, A. J., Al-Turki, K. A., Al Elq, A. H., El-Zubaier, A. G., \& Bahnassy A. (2010). Prevalence of diabetes mellitus and impaired fasting glucose levels in the Eastern Province of Saudi Arabia: results of a screening campaign. Singapore Medical Journal, 51(12), 923-930.

Al-Ghamdi, A. J., Al-Turki, K. A., Al-Baghli, N. A., \& El-Zubaier, A. G. (2007). A community-based screening campaign for the detection of diabetes mellitus and hypertension in the eastern province, saudi arabia: methods and participation rates. Journal of Family \& Community Medicine, 14(3), 91-97.

Ali, A. D., Mehrass, A. A., Al-Adhroey, A. H., Al-Shammakh, A. A., \& Amran, A. A. (2016). Prevalence and risk factors of gestational diabetes mellitus in Yemen. International Journal of Women's Health, 8, 35-41. http://dx.doi.org/10.2147/IJWH.S97502

Al-Nohair, S. (2014). Obesity in gulf countries. International Journal of Health Sciences (Qassim), 8, 79-83.

Al-Nozha, M. M., Al-Maatouq, M. A., Al-Mazrou, Y. Y., Al-Harthi, S. S., Arafah, M. R., Khalil, M. Z., ... Al-Mobeireek, A. (2004). Diabetes mellitus in Saudi Arabia. Saudi Medical Journal, 25(11), 1603-1610.

Al-Shehri, F. S., Moqbel, M. M., Al-Khaldi, Y. M., Al-Shahrani, A. M., Abu-Melha, W. S., Alqahtani, A. R., ... Almoreished, T. F. (2016). Prevention and management of obesity: Saudi guideline update. Saudi J Obesity, 4 , $25-40$.

Amarasinghe, S., Balakumar, S., \& Arasaratnam, V. (2015). Prevalence and factors associated with metabolic syndrome among Tamils aged over 18 years in Jaffna district, Sri Lanka. Journal of Diabetes \& Metabolic Disorders, 14, 61. http://dx.doi.org/10.1186/s40200-015-0190-x

American Diabetes Association (ADA) (2011). Diagnosis and Classification of Diabetes Mellitus. Diabetes Care, 34(Suppl 1), S62-S69. http://dx.doi.org/10.2337/dc11-S062

Amin, T. T., Al Sultan, A. I., Mostafa, O. A., Darwish, A. A., \& Al-Naboli, M. R. (2014). Profile of non-communicable disease risk factors among employees at a Saudi university. Asian Pacific Journal of Cancer Prevention, 15(18), 7897-7907. http://dx.doi.org/10.7314/APJCP.2014.15.18.7897

Balaji, V., Madhuri, B. S., Paneerselvam, A., Arthi, T., \& Seshiah, V. (2012). Comparison of venous plasma glucose and capillary whole blood glucose in the diagnosis of gestational diabetes mellitus: A community-based study. Diabetes Technol Ther, 14, 131-134. http://dx.doi.org/10.1089/dia.2011.0060

Bisha, World Public Library. Retrieved January, 12, 2016, from: www.worldlibrary.org/articles/bisha

Connor, J. M. O., Millar, S. R., Buckley, C. M., Kearney, P. M., \& Perry I. J. (2013). The prevalence and determinants of undiagnosed and diagnosed type 2 diabetes in middle-aged irish adults. PLoS One, 8(11), e80504. http://dx.doi.org/10.1371/journal.pone.0080504

Dunstan, D. W., Kingwell, B. A., Larsen, R., Healy, G. N., Cerin, E., Hamilton, M. T., ... Owen, N. (2012). Breaking up prolonged sitting reduces postprandial glucose and insulin responses. Diabetes Care, 35(5), 
976-983. http://dx.doi.org/10.2337/dc11-1931

El-Hazmi, M. A. F., Al-Swailem, A. R., Warsy, A. S., Al-Meshari, A. A., Sulimani, R. A., \& Al-Swailem, A. M. (1996). A Study of Diabetes Mellitus in Saudis Project No. AT-MW-10. Retrieved January 12, 2016, from http://faculty.ksu.edu.sa/52876/My\%20books/A\%20study\%20of\%.20Diabetes\%20mellitus\%20in\%20Saudi \%20Arabia/A\%20Study\%20of\%20Diabetes\%20Mellitus.pdf

El-Shafie, K. \& Rizvi, S. (2010). Control of Hypertension among Type II Diabetics. Oman Medical Journal, 25(1), 32-36. http://dx.doi.org/10.5001/omj.2010.8

Ginter, E., \& Simko, V. (2012). Global prevalence and future of diabetes mellitus. Advnces in Experimental Medicine and Biology, 771, 35-41.

Hajar, S., Al Hazmi, A., Wasli, M., Mousa, A., \& Rabiu, M. (2015). Prevalence and causes of blindness and diabetic retinopathy in Southern Saudi Arabia. Saudi Medical Journal, 36(4), 449-455.

Hariri, S., Yoon, P. W., Qureshi, N., Valdez, R., Scheuner, M. T., \& Khoury, M. J. (2006). Family history of type 2 diabetes: A population-based screening tool for prevention? Genet Med, 8(2), 102-108. http://dx.doi.org/10.1097/01.gim.0000200949.52795.df

Heraclides, A., Chandola, T., Witte, D. R., \& Brunner, E. J. (2009). Psychosocial stress at work doubles the risk of type 2 diabetes in middle-aged women: evidence from the Whitehall II study. Diabetes Care, 32, 2230-2235. http://dx.doi.org/10.2337/dc09-0132

International Diabetes Federation (IDF). (2015). Diabetes Atlas (7th ed.). Retrieved December 12, 2015, from www.diabetesatlas.org/

Kamadjeu, R. M., Edwards, R., Atanga, J. S., Kiawi, E. C., Unwin, N., \& Mbanya, J. C. (2006). Anthropometry measures and prevalence of obesity in the urban adult population of Cameroon: An update from the Cameroon Burden of Diabetes Baseline Survey. BMC Public Health, 6, 228. http://dx.doi.org/10.1186/1471-2458-6-228

Karim, A., Ogbeide, D. O., Siddiqui, S., \& Al-Khalifa, I. M. (2000). Prevalence of diabetes mellitus in a Saudi community. Saudi Medical Journal, 21(5), 438-442.

Khatib, O. M. N., \& El-Guindy, M. S. (2005). Clinical guidelines for the management of hypertension. World Health Organization Regional Office for the Eastern Mediterranean. Cairo: World Health Organization, Regional Office for the Eastern Mediterranean. Retrieved October 23, 2015, from www.emro.who.int/

Kyari, F., Tafida, A., Sivasubramaniam, S., Murthy, G. V., Peto, T., \& Gilbert, C. E. (2014). Nigeria National Blindness and Visual Impairment Study Group. Prevalence and risk factors for diabetes and diabetic retinopathy: results from the Nigeria national blindness and visual impairment survey. BMC Public Health, 14, 1299. http://dx.doi.org/10.1186/1471-2458-14-1299

Larsen, R. N., Kingwell, B. A., Sethi, P., Cerin, E., Owen, N. \& Dunstan, D. W. (2014). Breaking up prolonged sitting reduces resting blood pressure in overweight/obese adults. Nutrition Metabolic, Cardiovascular Diseases, 24(9), 976-982. http://dx.doi.org/10.1016/j.numecd.2014.04.011

Midhet, F. M., Al-Mohaimeed, A. A., \& Sharaf, F. K. (2010) Lifestyle related risk factors of type 2 diabetes mellitus in Saudi Arabia. Saudi Medical Journal, 31(7), 768-774.

Murad, M. A., Abdulmageed, S. S., Iftikhar, R., \& Sagga, B. K. (2014). Assessment of the common risk factors associated with type 2 diabetes mellitus in jeddah. International Journal of Endocrinology, 616145. http://dx.doi.org/10.1155/2014/616145

Pourhoseingholi, M. A., Vahedi, M., \& Rahimzadeh M. (2013). Sample size calculation in medical studies. Gastroenterology and Hepatology from bed to bench, 6(1), 14-17.

Robert, A. A., Al Dawish, M. A., Braham, R., Musallam, M. A., Al Hayek, A. A., \& Al Kahtany, N. H. (2016). Type 2 Diabetes Mellitus in Saudi Arabia: Major Challenges and Possible Solutions. Current Diabetes Reviews. [Epub ahead of print]

Salam, M. A., \& Siddiqui, A. F. (2013). Socio-demographic Determinants of Compliance among Type 2 Diabetic Patients in Abha, Saudi Arabia. Journal of Clinical and Diagnostic Research, 7(12), 2810-2813. http://dx.doi.org/10.7860/JCDR/2013/6986.3708

Sherif, S., \& Sumpio, B. E. (2015). Economic development and diabetes prevalence in MENA countries: Egypt and Saudi Arabia comparison. World Journal of Diabetes, 6(2), 304-411. 
http://dx.doi.org/10.4239/wjd.v6.i2.304

Soegondo, S., Widyahening, I. S., Istantho, R., \& Yunir, E. (2011). Prevalence of diabetes among suburban population of Ternate--a small remote island in the eastern part of Indonesia. Acta Medica Indonesia, 43(2), 99-104.

Soriguer, F., Goday, A., Bosch-Comas, A., Bordiú, E., Calle-Pascual, A., Carmena, R., ... Vendrell, J. (2012). Prevalence of diabetes mellitus and impaired glucose regulation in Spain. The Diabet.es Study. Diabetologia, 55(1), 88-93. http://dx.doi.org/10.1007/s00125-011-2336-9

Thorp, A. A., Kingwell, B. A., Sethi, P., Hammond, L., Owen, N., \& Dunstan, D. W. (2014). Alternating bouts of sitting and standing attenuate postprandial glucose responses. Medicine and Science in Sports and Exercise, 46(11), 2053-2061. http://dx.doi.org/10.1249/MSS.0000000000000337.

Valdez, R., Yoon, P. W., Liu, T., \& Khoury, M. J. (2007). Family history and prevalence of diabetes in the U.S. population: the 6-year results from the National Health and Nutrition Examination Survey (1999-2004). Diabetes Care, 30(10), 2517-2522. http://dx.doi.org/10.2337/dc07-0720

WHO Expert Consultation. (2004). Appropriate body-mass index for Asian populations and its implications for policy and intervention strategies. Lancet, 363, 157-163. http://dx.doi.org/10.1016/S0140-6736(03)15268-3

WHO STEP wise approach to NCD surveillance. (2005). Country-specific standard report. Saudi Arabia. Retrieved October 23, 2015, from http://www.who.int/chp/steps/2005_SaudiArabia_STEPS_Report_EN.pdf

Xia, Z., Wang, Z., Cai, Q., Yang, J., Zhang, X., \& Yang, T. (2013). Prevalence and risk factors of type 2 diabetes in the adults in Haikou city, Hainan Island, China. Iranian Journal of Public Health, 42(3), 222-230.

Zaman, F. A., \& Borang, A. (2014). Prevalence of diabetes mellitus amongst rural hilly population of North Eastern India and its relationship with associated risk factors and related co-morbidities. Journal of Natural Science, Biology and Medicine, 5(2), 383-388. http://dx.doi.org/10.4103/0976-9668.136195

Zhao, X., Zhu, X., Zhang, H., Zhao, W., Li, J., Shu, Y., ... Li, Y. (2012). Prevalence of diabetes and predictions of its risks using anthropometric measures in southwest rural areas of China. BMC Public Health, $12,821$. http://dx.doi.org/10.1186/1471-2458-12-821

\section{Copyrights}

Copyright for this article is retained by the author(s), with first publication rights granted to the journal.

This is an open-access article distributed under the terms and conditions of the Creative Commons Attribution license (http://creativecommons.org/licenses/by/4.0/). 